ASSESSING THE SAFETY AND EFFICACY OF THE FDA:

THE CASE OF THE PRESCRIPTION DRUG USER FEE ACTS

Tomas J. Philipson

Ernst R. Berndt

Adrian H. B. Gottschalk

Matthew W. Strobeck

Working Paper 11724 
NBER WORKING PAPER SERIES

\title{
ASSESSING THE SAFETY AND EFFICACY OF THE FDA: THE CASE OF THE PRESCRIPTION DRUG USER FEE ACTS
}

\author{
Tomas J. Philipson \\ Ernst R. Berndt \\ Adrian H. B. Gottschalk \\ Matthew W. Strobeck \\ Working Paper 11724 \\ http://www.nber.org/papers/w11724
}

\author{
NATIONAL BUREAU OF ECONOMIC RESEARCH \\ 1050 Massachusetts Avenue \\ Cambridge, MA 02138 \\ October 2005
}

Corresponding author, email: t-philipson@uchicago.edu. For part of the time this research was undertaken, Philipson was on leave from the University of Chicago to the FDA and CMS as the Senior Economic Advisor to the Commissioner and Administrator, respectively. Research support to Philipson from The Milken Institute and to Berndt, Gottschalk and Strobeck from general funds at the Harvard-MIT Division of Health Sciences and Technology is gratefully acknowledged. We thank Ed Hass of the FDA and Roy Gross of MIT for their very significant assistance throughout this project. The views and opinions expressed in this paper are those of the authors, and do not necessarily reflect any official positions or policies of the institutions or companies with which they are or have been affiliated. The views expressed herein are those of the author(s) and do not necessarily reflect the views of the National Bureau of Economic Research.

(C)2005 by Tomas J. Philipson, Ernst R. Berndt, Adrian H. B. Gottschalk, and Matthew W. Strobeck. All rights reserved. Short sections of text, not to exceed two paragraphs, may be quoted without explicit permission provided that full credit, including $(\mathcal{C}$ notice, is given to the source. 
Assessing the Safety and Efficacy of the FDA: The Case of the Prescription Drug User Fee Acts Tomas J. Philipson, Ernst R. Berndt, Adrian H. B. Gottschalk, and Matthew W. Strobeck NBER Working Paper No. 11724

October 2005

JEL No. I1, H0

\section{ABSTRACT}

The US Food and drug Administration (FDA) is estimated to regulate markets accounting for about $20 \%$ of consumer spending in the US. This paper proposes a general methodology to evaluate FDA policies, in general, and the central speed-safety tradeoff it faces, in particular. We apply this methodology to estimate the welfare effects of a major piece of legislation affecting this tradeoff, the Prescription Drug User Fee Acts (PDUFA). We find that PDUFA raised the private surplus of producers, and thus innovative returns, by about $\$ 11$ to $\$ 13$ billion. Dependent on the market power assumed of producers while having patent protection, we find that PDUFA raised consumer welfare between $\$ 5$ to $\$ 19$ billion; thus the combined social surplus was raised between $\$ 18$ to $\$ 31$ billions. Converting these economic gains into equivalent health benefits, we find that the more rapid access of drugs on the market enabled by PDUFA saved the equivalent of 180 to 310 thousand life-years. Additionally, we estimate an upper bound on the adverse effects of PDUFA based on drugs submitted during PDUFA I/II and subsequently withdrawn for safety reasons, and find that an extreme upper bound of about 56 thousand life-years were lost. We discuss how our general methodology could be used to perform a quantitative and evidence-based evaluation of the desirability of other FDA policies in the future, particularly those affecting the speed-safety tradeoff.

Tomas J. Philipson

The Milken Institute and The University of Chicago

$1155 \mathrm{E} 60^{\text {th }}$ Street

Chicago, IL 60637

and NBER

t-philipson@uchicago.edu

Ernst R. Berndt

Sloan School of Management

MIT, E52-452

50 Memorial Drive

Cambridge, MA 02142

and NBER

eberndt@mit.edu
Adrian H. B. Gottschalk

Biogen Idec, Inc.

Matthew W. Strobeck

Westfield Capital 


\section{INTRODUCTION}

In virtually all developed countries, regulatory authorities provide public oversight of the safety and efficacy of prescription drugs, prior to their being approved for marketing. In the U.S., such oversight is conducted by the Food and Drug Administration (FDA). A central tradeoff facing the FDA, and argued by many to be the most central one, involves balancing two goals - fulfilling its mission set by Congress to assure the safety and efficacy of drugs, while at the same time advancing the public health by not slowing down or disabling the innovative process by which new medical products reach the market.

Critics of the FDA, domestic and foreign, appear on both sides of this tradeoff. Some observers have argued that the FDA is not taking enough time evaluating new drugs, thereby allowing unsafe drugs to be marketed, while others have argued that the agency is taking too long in doing so and therefore inflicting harmful effects on innovative returns and patient welfare. ${ }^{1}$ However, surprisingly, very little quantitative empirical evidence has been put forward to evaluate the degree to which the speed and safety tradeoff facing the FDA is being resolved efficiently. More generally, there seems to be no suggested quantitative methodology or framework for assessing the economic efficiency of the central speed-safety tradeoff of the agency. ${ }^{2}$ This is somewhat paradoxical, since despite the agency's strict adherence to evidencebased evaluation of products overseen, there is less evidence on its own safety and efficacy. Put differently, no product application would pass the FDA approval process with the quality and type of evidence that currently exists for evaluating the FDA policies themselves. The welfare consequences of this lack of methodology and systematic evidence may be quite substantial, as 
the FDA is estimated to regulate markets accounting for about $20 \%$ of consumer spending in the US.

Motivated by this lack of quantitative assessment of FDA policies, this paper proposes a general methodology to evaluate the common speed-safety tradeoff of FDA regulations. The methodology only relies on the most common form of data available surrounding the drug approval process, namely, the distribution of approval and withdrawal times of drugs as well as the distribution of sales of the approved drugs. We use these commonly available data to estimate the social value of a drug. As indicated in Figure 1, in this paper we interpret the overall social value of a drug as its yearly social welfare from the time of review and approval to the time of withdrawal, if the drug is withdrawn.

As shown in Figure 1, the annual social surplus occurs after the drug is reviewed and approved, then split up into consumer and producer surplus components while on the market, and vanishes completely once the drug is withdrawn (if ever). Therefore, if the drug is beneficial as it is in the figure, its overall social value falls with the review time and rises with the time until withdrawal. However, if the drug is harmful, as when the social surplus is negative and below the $\mathrm{x}$-axis in the figure, then its overall social value rises with the review time and falls with the time until withdrawal. The agency in general, and separate regulations in particular, influence aggregate social welfare by affecting the distribution of review and withdrawal times, as well as the magnitude and signs of the post-approval annual flows of social surplus.

We apply this framework to quantify the change in aggregate social welfare induced by major legislative acts comprised of the Prescription Drug User Fee Act (PDUFA) of 1992, later continued as PDUFA-II in 1997 and PUDFA-III in 2002. These legislative acts specified performance goals for the FDA in terms of faster review times, while levying taxes in the form 
of user fees on the sponsoring applicant for consideration of new and supplemental drug applications, as well as for existing manufacturing establishments and products. The user fee revenues obtained under PDUFA represent a substantial portion of the FDA's total revenues obligated to processing human drug applications, often estimated to be close to half of the funding of the drug review process. ${ }^{3}$ The implementation of PDUFA and its impact on the central speed-safety tradeoff of the agency can be envisaged in Figure 1; faster review of drugs involves a shift to the left of the surplus curve in Figure 1, which is accomplished with the additional resources generated from the user-fees, but with the potential consequence of less attention being devoted to the safety of the drugs approved, entailing a downward shift in the surplus curve of Figure1 together with a reduction in withdrawal times.

To estimate the impact of PDUFA on aggregate social welfare, we first assess the impact of these Acts on review times using 662 New Molecular Entity (NME) drug approvals in the years 1979-2002 prior to and following enactment of the Acts in 1992. We find that even though there was a decline in review times of 2 percent a year prior to PDUFA, passage and implementation of PDUFA I and II accelerated the decline by 6-7\% and 3-4\% a year respectively. Using the estimated effects of PDUFA on approval times for each of the drug approvals, we are then able to estimate the counterfactual approval time that would have occurred in the absence of PDUFA.

The estimated effects in review times induced by PDUFA are first used to assess the impact on producer surplus or variable profits. One of the main issues of the speed-safety tradeoff facing the FDA is how PDUFA affects innovative returns. The revenues of a drug under PDUFA are derived from actual sales data, and the counterfactual revenues come from delaying the entry of the drug by the predicted drug-specific delay between the observed and 
counterfactual review times in a world with and without PDUFA. To estimate the effect of PDUFA on the innovative return of the drug, we then net out from the earlier arrival of its sales the application, product, and establishment fees associated with the drug under PDUFA as well as variable costs estimated by price levels before patents have run out and extensive entry of generic drugs has occurred. Our main finding is that producer surplus rose with the introduction of PDUFA by about $\$ 11$ billion or 1.2 percent (at a real discount rate of $3 \%$ and measured in 1992 dollars at the inception of PDUFA). For the sample of 284 drugs for which we had sales information during PDUFA I and PDUFA II, this represents a gain of about \$39 million per drug launched.

We then consider estimation of the social surplus from the additional speed induced by PDUFA through adding estimates of consumer surplus to the estimated producer surplus levels. We focus our discussion on two ways of adding consumer surplus to compute the social benefits of PDUFA. The first case occurs when full price discrimination is infeasible so that some consumer surplus exists under the patent. We use as a benchmark the case when consumer surplus is half of producer surplus, as turns out to be true when demand is linear and there are constant returns to scale. Also, under no price discrimination, we derive the simple but plausible conditions under which measures of sales, the most commonly available data on drug usage, constitute a lower bound to the social surplus. The second case occurs when price discrimination is complete so that there is no consumer surplus during the patent period but only after generics have entered. In this case, sales during the patent period represent producer surplus, and sales just prior to expiration represent the consumer surplus after the patent has expired. Our major findings here are that under no price discrimination, the social surplus generated by the greater speed of PDUFA is $\$ 31$ billion or 1.2 percent under demand linearity and constant returns to 
scale, but bounded below by $\$ 21$ billion or 1.2 percent under less stringent demand and cost assumptions. For the case of complete price discrimination, we find that the benefit of the additional speed is $\$ 18$ billion or 1.2 percent. For the 284 drugs with sales data, these estimates amount to a gain of about $\$ 109$ or $\$ 62$ million per drug introduced since the inception of PDUFA.

These evaluations of the social benefits of speed are then compared to the social costs of a possibly less safe approval process. To assess the impact on consumer safety, we first consider the effect PDUFA had on the fraction of drugs withdrawn and how rapidly they were withdrawn. However, these measures of the quantity and timing of withdrawal do not fully capture the quality of the drugs withdrawn. We also compute how much harm to health PDUFA must have imposed in order to offset the gains from speed due to more rapid review. Our major findings are that the proportion and timing of withdrawal of drugs approved pre- and post-PDUFA do not differ in a statistically significant way; about $2-3 \%$ of approved drugs are withdrawn at the same speed before and after the Acts. In addition, we compute an extreme upper bound on the adverse safety effects induced by PDUFA by assuming that all NME withdrawals after 1992 were due to PDUFA and that the were no benefits associated with the drugs so that their social surplus is measured by the harmful health effects the withdrawn drugs imposed. Using this extreme upper bound on the adverse safety effects of PDUFA, we find that the drugs approved and withdrawn during PDUFA cost about 56 thousand life years as compared to the gains in health implicit in the greater speed generated by PDUFA, which are estimated at the equivalent of 180 to 310 thousand life years. This estimate comes from dividing the value induced by speed for the different social surplus cases by a range of estimates for the value of a life year, between $\$ 100,000$ to $\$ 300,000$. 
The paper proceeds as follows. In Section II we provide a general framework for assessing quantitatively the value of changes to the speed-safety tradeoff facing the FDA. In Section III we provide a brief overview of PDUFA-I and PDUFA-II. In Sections IV and V, we discuss estimation of the beneficial speed effects of PDUFA on producer, consumer, and social welfare, using methods of bounding social surplus from sales data. In Section VI we estimate negative safety effects of PDUFA by considering their effects on drug withdrawals as well as calculating the equivalent losses in social surplus or health that must be induced to offset the observed benefits of speed. Finally, in Section VII we summarize our findings, note limitations of our research, and suggest directions for further research.

\section{A FRAMEWORK FOR EVALUATING CHANGES IN THE SPEED-SAFETY TRADEOFF OF THE FDA}

This section discusses a parsimonious framework for evaluating changes in FDA policy that affect the speed-safety tradeoff. Let $\mathrm{p}(\mathrm{y})$ denote the inverse demand curve for a drug in a given year and let $\mathrm{c}(\mathrm{y})$ be the cost function where $\mathrm{y}$ represents output. The annual producer $\pi(\mathrm{y})$ and consumer surplus $\mathrm{s}(\mathrm{y})$ are specified in a standard manner as

$$
\begin{aligned}
& \pi(y)=p(y) y-c(y) \text { and } \\
& \mathrm{s}(\mathrm{y})=\int_{0}^{y}[p(q)-p(y)] d q .
\end{aligned}
$$

This specification could be modified to other forms of non-canonical producer and consumer surplus relationships, e.g., representing insurance coverage of consumers or asymmetric information about risks between consumers and producers. Regardless of how surpluses are specified, we denote by $\mathrm{w}$ a vector of annual surpluses where each element $\mathrm{w}_{\mathrm{t}}=\mathrm{s}_{\mathrm{t}}+\pi_{\mathrm{t}}$ is the annual social surplus $t$ years after the drug is first marketed. We assume throughout that either $\mathrm{w} \geq 0$ or $\mathrm{w} \leq 0$, that is, the drug is either always valued or not for all periods. Given these annual social 
surplus levels, a drug that is approved at date a and is on the market for a duration of m periods, has the realized social welfare

$$
\mathrm{W}(\mathrm{a}, \mathrm{m}, \mathrm{s}, \pi)=\beta^{\mathrm{a}} \int_{0}^{m} \beta^{\mathrm{t}} \mathrm{w}_{\mathrm{t}} \mathrm{dt}=\beta^{\mathrm{a}} \int_{0}^{m} \beta^{\mathrm{t}} \mathrm{s}_{\mathrm{t}} \mathrm{dt}+\beta^{\mathrm{a}} \int_{0}^{m} \beta^{\mathrm{t}} \pi_{\mathrm{t}} \mathrm{dt}=\mathrm{S}+\Pi
$$

This realized surplus implies that if a drug has social value every period, $w>0$, the overall welfare falls in the approval time and rises in the time on market; i.e., $\mathrm{dW} / \mathrm{da}<0$ and $\mathrm{dW} / \mathrm{dm}>0$. In other words, speeding up the entry of a valuable drug or postponing its exit both raise social surplus. On the other hand, if the drug is socially harmful every period, $\mathrm{w}<0$, the welfare rises in the approval time and falls in the market time, i.e., $\mathrm{dW} / \mathrm{da}>0$ and $\mathrm{dW} / \mathrm{dm}<0$. In other words, delaying a harmful drug or shortening its time on the market both raise social welfare. Note here that non-approval and non-withdrawal of a drug can be represented by infinite values of a, for which $\mathrm{W}$ is zero as no surplus is realized, and $\mathrm{m}$, in which case we assume the annual surplus eventually decreases with time due to therapeutic and generic competition, making the welfare well defined.

Given that drugs are patent protected, the social surplus, and its share attributable to consumers versus producers, may differ across years since the drug has been marketed. In particular, the social surplus $\mathrm{w}_{\mathrm{t}}=\mathrm{s}_{\mathrm{t}}+\pi_{\mathrm{t}}$ for the $\mathrm{t}^{\text {th }}$ year the drug is on the market depends on the length of the patent $\tau$. Given a patent length, the producer surplus mainly obtains from the profits while on patent, when $t \leq \tau$. Indeed, we will assume that the present value of profits after patent expiration at the time of launch is zero not only due to generic competition but also due to discounting. As opposed to the case for producer surplus, the annual consumer surplus is lower during the patent period and occurs mainly after the patent has expired, when $t \geq \tau$, as producer surplus is then substituted for consumer surplus. 
For a total of $\mathrm{N}$ applications with the distribution $\mathrm{F}(\mathrm{a}, \mathrm{m}, \mathrm{s}, \pi)$ of approval times, market times, and surplus levels, the aggregate social welfare, A, can be broken down into a consumer and producer component as follows:

$$
\mathrm{A}=\mathrm{N} \int \mathrm{WdF}=\mathrm{N} \int \mathrm{SdF}+\mathrm{N} \int \Pi d \mathrm{~F} .
$$

Now consider the impact of the FDA on the aggregate social welfare A. Assume that the drugs considered under the FDA are represented by $(\mathrm{N}, \mathrm{F})$ and the drugs without the FDA are represented by $\left(\mathrm{N}_{\mathrm{o}}, \mathrm{F}_{\mathrm{o}}\right)$. It seems warranted to assume that a drug would be marketed faster without the FDA, $a_{0} \leq a$, that it would remain on the market longer without the FDA as the producer can voluntarily exit in the presence of the FDA, $\mathrm{m} \leq \mathrm{m}_{\mathrm{o}}$, and that the drug pipeline would be more numerous without the FDA as the agency raises $R \& D$ costs, $N \leq N_{0}$. Therefore, if the drug is valuable, then $\mathrm{W}(\mathrm{a}, \mathrm{m}) \leq \mathrm{W}\left(\mathrm{a}_{\mathrm{o}}, \mathrm{m}_{\mathrm{o}}\right)$, and the FDA generates a social cost due to the less rapid and potentially barred marketing of the drug and the potential that it is withdrawn for undue reasons:

$$
\mathrm{C}=\mathrm{NE}[\mathrm{W} \mid \mathrm{w} \geq 0]-\mathrm{N}_{\mathrm{o}} \mathrm{E}_{\mathrm{o}}[\mathrm{W} \mid \mathrm{w} \geq 0] \leq 0 .
$$

This term is negative because when the drug is socially valuable, the welfare falls in the approval time and rises in the market time $\mathrm{m}$, so if the agency raises a and reduces $\mathrm{m}$, then it lowers welfare. On the other hand, if the drug is socially harmful, then $\mathrm{W}(\mathrm{a}, \mathrm{m}) \geq \mathrm{W}\left(\mathrm{a}_{\mathrm{o}}, \mathrm{m}_{\mathrm{o}}\right)$ and the FDA confers a benefit by delaying or barring marketing of the drug or getting it off the market faster; hence

$$
\mathrm{B}=\mathrm{NE}[\mathrm{W} \mid \mathrm{w}<0]-\mathrm{N}_{\mathrm{o}} \mathrm{E}_{\mathrm{o}}[\mathrm{W} \mid \mathrm{w}<0] \geq 0
$$

This term represents the gain in welfare due to increased safety from keeping unsafe drugs off the market and, when approved, speeding up their withdrawal. This term is positive because 
when the drug is unsafe, welfare rises in the approval time a and falls in the market time $\mathrm{m}$ so that if the agency raises the approval time and lowers the market time, social welfare rises.

The overall welfare effect depends on the benefits of more quickly eliminating or removing unsafe drugs versus the costs of reduced speed of market entry of safe and efficacious drugs, i.e.,

$$
A-A_{o}=\operatorname{Pr}\{w<0\} B+\operatorname{Pr}\{w \geq 0\} C .
$$

The agency thus has two opposing effects; one harmful (speed effect for valuable products) and one beneficial (more speedy elimination effects for unsafe products). These two components of aggregate welfare comprise the essential speed vs safety tradeoff of the FDA analyzed in this paper. The effects are exemplified by changes in behaviors surrounding PDUFA which may be interpreted as moving away from $\mathrm{A}$ towards $\mathrm{A}_{\mathrm{o}}$ through speeding up approval but potentially increasing safety issues. Note that the speed element central to the FDA makes the two components of welfare depend on elements of the distribution $\mathrm{F}$ in addition to the classic type I and II errors represented by the share of bad drugs approved, $\operatorname{Pr}\{\mathrm{a}<\infty \mid \mathrm{w}<0\}$, and the share of good drugs not approved, $\operatorname{Pr}\{a=\infty \mid w>0\}$. Rather, it is the timing of the decisions made that matters and that needs to be explicitly incorporated into any methodology evaluating agency approval behavior.

Our empirical analysis will estimate the impact of PDUFA on the aggregate welfare A. In particular, we will estimate the first term in the change from A towards $A_{o}$ induced by PDUFA, the value of the greater speed induced by the legislative acts. Thereafter we compute the equivalent loss in health, in terms of life years lost, that any offsetting increase in the second term, due to a lowered safety of the approval process, must have to offset the benefits of this increased speed. In doing so, we will estimate the impact of PDUFA on the distribution of 
approval times $\mathrm{F}(\mathrm{a})$, the distribution of market times $\mathrm{F}(\mathrm{m})$, and use these with estimates of the producer and consumer surplus distribution $\mathrm{F}(\pi, \mathrm{s})$ to calculate the induced change in aggregate social surplus A.

\section{ESTIMATING THE BENEFITS OF SPEED DUE TO PDUFA}

\section{A. Background on PDUFA ${ }^{4}$}

The concept of payment of user fees by individuals or firms being provided services by a government regulatory body has ample precedent, e.g., application submission fees to the U.S. Patent and Trademark Office. The development of the Prescription Drug User Fee Act permitted the FDA to collect fees from sponsors submitting a New Drug Application (NDA or Biologics License Application (BLA) for review. The passage of PDUFA-I in 1992 was, however, somewhat controversial in that the amount of fees collected for each sponsor application was very substantial, unlike that for patent applications. In the initial fiscal year 1993 user fee schedule, applications with clinical data were assessed a one-time fee of $\$ 100,000$; each supplemental application with clinical data, and applications with no clinical data, $\$ 50,000$; annual manufacturing establishment fees were $\$ 36,080$, and annual product fees were $\$ 6,000$. With effective renewals of PDUFA-I in 1997 under the Food and Drug Modernization Act of 1997 ("PDUFA-II") and the Bioterrorism Preparedness and Response Act of 2002 ("PDUFAIII"), fees have escalated sharply. In fiscal year 2004, for example, applications with clinical data were assessed a one-time fee of $\$ 573,500$; each supplemental application with clinical data, and applications with no clinical data, were assessed a user fee of $\$ 286,750$; annual manufacturing establishment fees were $\$ 226,800$, and annual product fees were $\$ 6,000$. Waivers 
and exemptions were granted to small firms, and to sponsors submitting an application under the Orphan Drug Act of 1983. ${ }^{5}$

In exchange for the collected user fees, the FDA was legally obliged to "review and act on" NDA/BLA submissions. However, similar to the journal referee process in the academic environment, reviewing and acting on is not the same as reaching a final approval decision. According to the PDUFA-III legislation, for example:

" 'review and act on' is understood to mean the issuance of a complete action letter after the complete review of a filed complete application. The action letter, if it is not an approval, will set forth in detail the specific deficiencies and, where appropriate, the actions necessary to place the application in condition for approval.",6

In essence, therefore, PDUFA mandates responses and action letters from the FDA, but not necessarily approvals or final denials.

NDA/BLA submissions are assigned either a "standard" or "priority" status, depending in part on the novelty of the therapeutic and the existence of unmet needs. In the case of PDUFA-I, II and III, the FDA is required to deliver a "complete review" on $90 \%$ of priority applications within six months. For standard applications, the FDA was obliged to review $90 \%$ of applications in twelve months under PDUFA-I; currently, the FDA is mandated to review 90\% of standard applications within ten months.

On the action date mandated by PDUFA, the FDA issues one of three possible actions. The first is a non-approvable letter indicating that the NDA/BLA has not satisfied the FDA's standards for safety and/or efficacy. The second is an "approvable" letter that indicates the NDA/BLA can be approved if certain deficiencies and questions are appropriately acted upon by the sponsor. The third type of action is the ultimate approval letter that gives the sponsor 
company the right to market the drug to the public. Although PDUFA action date mandates have generally been met by the FDA, these action dates are not the same as approval dates.

To assess the impact of PDUFA on approval times, we considered drug approval data provided to us by the FDA. These data indicate that approval times have been falling for quite some time, at least since 1979, and appear to suggest that approval time declines have accelerated, particularly during PDUFA-I. For example, mean approval time during 1979-86 was 33.6 months, 28.2 months in 1987-92, 18.6 months during PDUFA-I, and 16.1 months during PDUFA-II. Since the approval time data is skewed to the right, the corresponding median approval times are all smaller, but they too fall over time: 27.1 (1979-86), 23.8 (1987-92), 16.2 (PDUFA-I), and 12.3 (PDUFA-II).

One way of depicting drug approval time trends is to construct "survival" curves that plot the proportion of approvals not yet completed within a fixed time period. More precisely, the "survival" curve in Figure 2 plots the percent approvals remaining over time in months, one curve for each of the time periods 1979-86, 1987-92, PDUFA-I and PDUFA-II.

Survival curves from more recent time periods are clearly separate from and ever closer to the origin than are those from earlier eras. The more rapid decline in survival curves during PDUFA-I and II relative to the pre-PDUFA time period indicates faster approvals. Note that the horizontal line designated with a $90 \%$ rate in the graph intersects the various survival curves at far longer time periods than those stated by the PDUFA goals, since the PDUFA goals involved review times rather than approval times.

\section{B. Estimating The Effects of PDUFA on The Approval Time Distribution F(a)}

To estimate the incremental impact of PDUFA on approval times empirically, we used data on 662 NMEs, small molecule chemicals and biological agents, submitted to the FDA for 
review on a government fiscal year basis between October 1, 1979 and September 30, 2002. Initially we report here the main results contained in Berndt et al [2005] ${ }^{7}$, where we only assessed the effects on review times and thus did not propose and perform the economic evaluation discussed here.

We estimated parameters in multivariate regression specifications in which the dependent variable was the natural logarithm of the time between NDA/BLA submission and final FDA approval. An annual time trend counter variable $(1979=1,2002=23)$ was included as a regressor, as were 0-1 PDUFA-I and PDUFA-II indicator variables, the latter two interacted with another time trend counter $(1992 / 1993=1,2001 / 2002=10)$.

Several additional explanatory variables were added to account for potentially confounding non-PDUFA effects (e.g., efforts by oncology and HIV/AIDS patient advocacy groups). These variables included binary (0-1) variables for whether the application was submitted under the Orphan Drug Act provisions, whether the application was designated a Priority Review status, and whether the sponsor was domestic versus foreign. To account for differential clinical difficulties in the development process, the time in clinical development (natural logarithm of time between the Initial New Drug Application (IND) and the NDA/BLA submission) was added as a regressor, as were 0-1 indicator variables for twelve therapeutic classes (cardiovascular, anti-infective, anti-neoplastic, CNS, AIDS, metabolic/endocrine, gastrointestinal, dermatology/ophthalmology, anti-inflammatory, radiopharmaceuticals, respiratory and other, with biologics being the omitted reference case). To allow for therapeutic class-specific time trends, each of the twelve therapeutic class indicator variables was interacted with the PDUFA-I and PDUFA-II time trend interaction variables. Analysis revealed that only in two therapeutic areas (anti-inflammatory and anti-neoplastic) were PDUFA-related time 
trends different from the overall trends. Regression results with and without the differential antiinflammatory and anti-neoplastic PDUFA-related trends are given in Table 1.

In the specification assuming equal time trends across therapeutic classes (first column of Table 1), the parameter estimate on the overall time trend suggests an annual decline of about $1.7 \%$ in approval times; the negative coefficients on the PDUFA-I and II variables imply that this decline accelerated to about 9-10\% annually during PDUFA-I, and then declined at a slightly slower rate of about 5\% during PDUFA-II. When differential therapeutic class PDUFA-related time trends are permitted (the second set of columns in Table 1), the pre-PDUFA and postPDUFA annual declines for most therapeutic classes remain the same as in the more restricted specification. However, during PDUFA-II, the annual declines in approval time for antiinflammatory drugs approach $15 \%$, while those for anti-neoplastic agents reach about $10 \%$. In both specifications, as expected, the regression analysis revealed shorter approval times for priority vs. standard review (-0.490 exponentiated, about 38\%).

In terms of therapeutic class effects, since the regression coefficients are relative to the biologics class, controlling for other confounding variables, approval times were shortest for AIDS applications (about 56\% shorter than biologics), about 30\% shorter for the "other" class, and about $25 \%$ shorter for applications in the anti-infective and anti-neoplastic therapeutic classes; each of these was statistically significantly shorter than that for biologics (p-values < 0.05). The only class for which approval times were significantly longer than biologics both preand post-PDUFA was that for respiratory agents (about 33\% longer). 


\section{THE EFFECT OF PDUFA ON PRODUCER SURPLUS}

We now report results from estimating the effects of PDUFA on the total producer surplus $\int \Pi d F$, which represents the innovative return of the drug after R\&D has been undertaken. PDUFA affects an innovator's returns by raising both the costs and the benefits of innovation. The cost is raised by the amount of the use fee taxes levied, while the benefit is raised by the gains in the present value of the innovator's return induced by the more rapid FDA approval.

The effect of faster approval on producer surplus is the difference between the surplus under the observed approval time and the counterfactual approval time for that drug with PDUFA interaction variables set to zero in the estimated approval time multivariate regression specifications discussed in the previous section. A similar set of calculations can be undertaken to compute the present value of the additional user fee costs associated with PDUFA for a given drug. The net gain in the present value of an innovative return is then computed by netting out the user fees from the gains due to faster approvals since the inception of PDUFA, all in present values.

To implement these calculations empirically, several estimation issues must be resolved regarding the discount rate, the estimation of sales profiles and the estimation of drug specific taxes or user fees. First, we implement the innovative return calculations using a range of real discount rates from 3 to 9 percent. $^{8}$

Second, data are needed on actual and predicted sales of drugs over their life cycle, as well as actual and predicted PDUFA user fees. Through a third party agreement with IMS Health Inc., the FDA provided us comprehensive retail plus hospital sales data for all drugs on the U.S. market from February 1998 through December 2002. The sales data included the following channels: independent pharmacies, chain pharmacies, mass merchandisers with and 
without pharmacies, mail order pharmacies, food stores with pharmacies, non-federal hospitals, federal facilities, clinics, long-term care facilities, home health care, closed HMOs, and miscellaneous channels (starting in 1999, prisons, universities and other). ${ }^{9}$ Given that many drugs were approved prior to 1998 and that data on future sales beyond 2002 were unavailable, estimates of sales outside years 1998 through 2002 were needed. IMS Health has reported results of an analysis of launch to peak sales for new chemical entities, based on 816 new chemical entities launched since 1983 (information on the terminal year is not available). ${ }^{10}$ Results from this analysis relate over a 15-year life cycle the average yearly sales as a percent of peak sales. Although the IMS analysis found that a drug on average reached its peak sales 13 years after launch, sales in years 10 through 13 are relatively flat, and then drop off precipitously. ${ }^{11}$ Based on the IMS data and analysis, for each drug, sales were first annualized if the available sales data did not begin in January of a given year. ${ }^{12}$ Predicted peak sales for that drug were then computed using the IMS life cycle year to peak percentages, as were sales for all other years not observed in the IMS data. All sales were then deflated to 1992 dollars using the GDP deflator.

Third, incremental costs associated with PDUFA include calculations of the present value of PDUFA user fees. PDUFA fees consist of application fees, establishment fees, and product fees; as noted earlier, these have risen sharply since 1992. PDUFA fees for 2005 and forward were estimated based on the compound annual growth rates (CAGR) observed from 1993 to 2004. Given that the US Congress has renewed PDUFA in 1997 and 2002, and given that the renewal year has generated a much larger percentage increase in the user fee schedule than the relatively minor subsequent increases within PDUFA-I, PDUFA-II, and PDUFA-III, we forecasted significant increases for 2008 and 2013, the next times PDUFA will likely need to be 
reauthorized. Specifically, we constructed large percentage increases in reauthorization years and subsequent minor increases between reauthorizations so as to yield a CAGR in real user fees of $15 \%$, approximately equal to that observed historically. Similar to the sales curves, the actual PDUFA fees were deflated to 1992 dollars using the GDP deflator.

Novel NDA/BLA application fees were charged during the year of an NDA/BLA submission to the FDA. Product fees and establishment fees were allocated during each year of sales. We allocated $100 \%$ of the establishment fee to each NME. This likely overstates such fees, since many establishments manufacture more than one drug or biologic; informal conversations with the FDA indicated that on average, approximately three drugs/biologics are manufactured per location. This allocation therefore biases upward the user fee cost calculations. It was also necessary to forecast the number of future supplemental applications, since detailed information is not yet readily available to us. From PDUFA performance reports of 1997, 1999 and 2003, we noted that between 1993 and 2003, a total of 1,266 original NDAs/BLAs were filed at the FDA (not all of which were, of course, approved). Over the same time period, 1,518 efficacy supplements were also filed (of which how many were approved we do not know). The ratio of filed supplements to filed original NDAs/BLAs over this time period is 1.199. Since it is plausible to expect that the proportion of supplemental submissions approved by the FDA is larger than the proportion of novel NDA/BLA submissions that is approved, we expect the actual number of supplementals approved for each approved NDA/BLA to be larger than 1.199. We therefore make the assumption that for every approved NDA/BLA, two supplemental applications are submitted in the second year post market launch. This is a relatively "conservative" assumption in that 2.0 is a large number, and that the timing of both supplements being in the second year post launch likely overstates the rapidity with which such 
supplementals are filed. ${ }^{13}$ These assumptions on supplementals therefore bias upwards the present value of the PDUFA supplemental user fees. Since supplemental NDAs/BLAs do not increase the product fee or establishment fee already being paid by a sponsor, no further adjustments are made.

Table 2 reports our principal findings for the effect of PDUFA on producers' innovative returns, based on assumptions regarding the share of variable costs of revenues and the real discount rate. Our estimates of the share of sales that are attributable to costs are from existing estimates in the literature. For example, using generic prices several years after initial generic entry as an estimate of marginal costs, and based on data from the 1980s and early to mid-1990s, Grabowski and Vernon [1992] and Berndt, Cockburn, and Griliches [1996] report that in most cases the brand price is more than four times the estimated marginal costs. ${ }^{14}$ In Table 4 we therefore set variable costs equal to $20 \%$ of sales revenue, for drugs during patent protection.

Table 2 indicates that the aggregate gains in producer surplus ranged from $\$ 14$ billion (\$11 billion with PDUFA and variable costs removed) under a 3\% real discount factor to $\$ 17$ billion (\$13 billion with PDUFA and variable costs removed) under a 9\% real discount factor. These gains in producer surplus incorporate the additional user fee costs of PDUFA represented by an aggregate amount of about $\$ 890 \mathrm{M}$ in present value in the case of a 3\% discount rate and \$390M under a 9\% discount rate.

\section{THE EFFECT OF PDUFA ON SOCIAL SURPLUS}

Next we report results from estimating the effects of PDUFA on the total social surplus $\int \mathrm{WdF}$ by augmenting the estimated effects of PDUFA on producer surplus $\int \Pi d F$ by the estimated effects on consumer surplus $\int \mathrm{SdF}$. However, as opposed to the producer surplus, the annual 
consumer surplus is lower during the patent period, when it is limited by the degree of market power by the patent holder, than after the patent has expired, when prices come down and consumer surplus rises. Annual consumer and social surplus calculations must therefore differentiate between pre- and post patent expiration, whereas this was not a major issue when producer surplus was assumed zero after patent expiration.

In estimating social surplus, we are interested in how one can use readily available sales data in order to provide a bound on the social surplus before and after expiration. Regardless of the form of the inverse demand and variable cost functions, sales bound social surplus from below when

$$
\pi+\mathrm{s} \geq \mathrm{py}
$$

Substituting in for $\pi(\mathrm{y})$ and rearranging yields

$$
\mathrm{s} \geq \mathrm{c},
$$

i.e., consumers' surplus is at least as large as variable costs. This holds because sales understate social surplus by the amount of consumer surplus, and overstate social surplus by the costs of production. Sales always overstate producer surplus, but understate social surplus if variable costs are small and there is some consumer surplus.

The degree to which sales captures the social surplus depends on the extent of market power. Let $f$ be the fraction of social surplus captured by the producer as defined by

$$
\mathrm{f}=\mathrm{f}[\pi+\mathrm{s}] .
$$

Under perfect competition the fraction $\mathrm{f}$ attains its minimum value of zero and the consumers capture the entire surplus. At the opposite extreme, when producers have sufficient market power to perfectly price discriminate, this share attains its maximum value of unity. Given the extent to 
which producers capture social surplus, we can rewrite the condition when sales bound social surplus according to

$$
(1 / f) \pi \geq p y,
$$

which when rewritten becomes

$$
\mathrm{p} /[\mathrm{c} / \mathrm{y}] \geq 1 /(1-\mathrm{f})
$$

This states that if the average markup is above a threshold level, sales provide a lower bound on surplus. A special case, potentially applicable to pharmaceuticals when sales perfectly measure social surplus, is when the producer captures the entire surplus through perfect price discrimination and variable costs are ignorable; $1-\mathrm{f}=\mathrm{s}=\mathrm{c}=0$.

To illustrate, consider the often estimated constant returns case with a linear demand function, as in $\mathrm{p}(\mathrm{y})=\mathrm{a}-\mathrm{by}$ and $\mathrm{c}(\mathrm{y})=\mathrm{cy}$. In this case, regardless of $(\mathrm{a}, \mathrm{b}, \mathrm{c})$, the fraction of surplus captured by the producer is $\mathrm{f}=2 / 3$, so that sales bound social surplus from below whenever the variable cost to price ratio is less than a third : $c / p<1 / 3$. This follows from the result that in this case the monopoly output is half the competitive output, which implies that consumer surplus is half the profits.

Using these bounding methods to identify consumer and social surplus from sales data, we report in Table 3 our principal findings on the estimated effects of PDUFA on these quantities.

The various rows in Table 3 are calculated in a relatively straightforward fashion. The sales bound for the social surplus before expiration (Row A) is simply the present value of gross sales over a 15 year time period under patent protection. Variable costs and PDUFA fees are not subtracted. In all cases, the counterfactual calculations use our regression specification to predict the delay in approval time, which increases the number of years the 15 -year sales curve is 
discounted. The sales bound on social surplus after patent expiration (Row B) is calculated as a 15-year decreasing annuity with the initial payment being the average of the last three years of sales for each product while on patent. This annual payment then decreases by $10 \%$ per annum and is discounted back to 1992 . The calculations are done on a drug by drug basis and then aggregated.

We next calculate cases for the highest consumer surplus (corresponding to a linear demand curve and constant returns) and lowest consumer surplus (producer captures entire social surplus during time of patent protection). The highest case before patent expiration (Row C) is calculated as $50 \%$ of the net sales that are shown in Table 2 for both PDUFA and the counterfactual scenario. For the case after patent expiration (Row D), we double the post-patent expiration social surplus sales bound (Row B). If we sum the pre- and post-patent expiration periods for the highest case, we obtain the total consumer surplus (Row E). We can then add the producer surplus, calculated with PDUFA and variable costs removed in Table 2, to obtain the total social surplus in the highest case (Row F). For the case of the lowest consumer surplus, we assume that the consumer does not accrue any benefit prior to patent expiration (Row $G=0$ ). After patent expiration, the consumer accrues a surplus equal to the lower bound of the social surplus (Row H), which was calculated in Row B. We can then sum the before- and after-patent expiration (Rows $\mathrm{G}$ and $\mathrm{H}$ ) to obtain the total consumer surplus for the lowest case scenario (Row I). To calculate the total social surplus under the lowest case scenario (Row J), we simply add the total consumer surplus we calculate here to the producer surplus in Table 2, which is net of PDUFA fees and variable costs.

Table 3 presents our major findings on the consumer and social surplus induced by the more rapid drug approvals associated with PDUFA. The first set of estimates measures lower 
bounds on social surplus represented by sales when price-cost margins are high on the patent together with the last year prior to patent expiration representing the annual surplus after patent expiration. This provides lower bounds on the social surplus during the patent and assumes the social surplus is the same after the expiration as during the expiration. Under a low (high) discount rate of 3\% (9\%), the table indicates that PDUFA I - II raised the estimated lower bound on social surplus by $\$ 14 \mathrm{~B}$ or $1.3 \%$ ( $\$ 17 \mathrm{~B}$ or $3.7 \%$ ) before patent expiration and $\$ 7 \mathrm{~B}$ or $1.2 \%$ (\$5B or $4 \%)$ after patent expiration.

The second set of estimates assumes a consumer surplus under a linear demand and constant marginal costs. In this case, during the patent the consumer surplus is half the producer surplus and after patent twice the producer surplus just prior to expiration. Under a low (high) discount rate of 3\% (9\%), Table 3 indicates that PDUFA I and II raised the high estimate of consumer surplus, comprised of both prior-and post-expiration levels, by $\$ 19 \mathrm{~B}$ or $1.2 \%$ ( $\$ 17 \mathrm{~B}$ or $3.8 \%)$. Together with the producer surplus estimates of roughly $\$ 11 \mathrm{~B}(\$ 13 \mathrm{~B})$ from the previous table, this amounts to a total increase in social surplus of $\$ 31 \mathrm{~B}$ or $1.2 \%(\$ 30 \mathrm{~B}$ or $3.7 \%)$.

The third set of estimates is the most conservative estimate of the consumer gains, and is based on the assumption that there is no consumer surplus while the drug is on patent. Because of the extensive market power of the patent-monopolist assumed in these estimates, the consumer surplus after the patent expires equals the producer surplus just prior to patent expiration. This represents a worst case scenario for consumers. Under a low (high) discount rate of 3\% (9\%), Table 3 indicates that PDUFA I and II raised the estimated consumer surplus by $\$ 7$ billion or $1.2 \%$ ( $\$ 5$ billion or $4 \%$ ) in this case. Therefore, even in this conservative case, there are substantial gains to consumers from the more rapid FDA approval of drugs during PDUFA I and II . 


\section{ESTIMATING THE SAFETY EFFECTS OF PDUFA}

The previous discussion reports findings from estimating the first term or speed component of the change in aggregate welfare A towards $\mathrm{A}_{\mathrm{o}}$ induced by the changes of PDUFA. In this section we discuss the second term representing any offsetting changes in safety that may have occurred. We also attempt to price out these safety deteriorations in terms of health effects.

\section{A. Estimating The Effects of PDUFA on The Market Time Distribution F(m)}

In a previous analysis, we have examined the impact of PDUFA on the market time distribution $\mathrm{F}(\mathrm{m})$ by considering the time until withdrawal of drugs pre- and post-PDUFA. Specifically, in Berndt et al. [2005] we have reported on various pre- and post-PDUFA withdrawal comparisons. ${ }^{15}$ Simple proportion comparisons involving the number of NMEs withdrawn prior to the passage of PDUFA I relative to the number of NMEs withdrawn during PDUFA I and II suggest that no difference exists between the two periods. However, these simple, naïve comparisons do not account for censoring of the data (limited observation time for post PDUFA NMEs compared to the pre-PDUFA cohort). In order more reliably to assess the potential difference between the cohort of NMEs with withdrawals prior to PDUFA to the cohort of NMEs with withdrawals after PDUFA, we constructed Kaplan-Meier curves (see Figure 3). Based on a log-rank test analysis, we concluded that we could not reject the null hypothesis that the two curves are identical ( $\mathrm{p}$-value of no difference $=0.39$ ). We note that all comparisons, whether simple proportion comparisons or Kaplan-Meier analysis, are heavily reliant on the determination of what NMEs belong in the numerator and in the denominator. More specifically, determining the actual distribution of NMEs withdrawn from market and assigning them to the appropriate cohort is reliant on three main factors. First, the definition of when the PDUFA legislation actually took effect and which NMEs were reviewed under the PDUFA 
guidelines is not definitive. Discussions with FDA personnel confirm that the legislation was passed as of late 1992 but that the actual effects of PDUFA were only affected sometime in 1993. The "flexibility" in timing can shift several NMEs (e.g., tamfloxacin, cisapride) between the pre-PDUFA and post-PDUFA cohorts.

Secondly, as discussed in our 2005 article, the definition of pre-PDUFA is ambiguous as well. For purposes of our analysis, we defined a time period from roughly 1980 forward; however, one could easily argue that the pre-PDUDFA period should extend further back in time. Our choice of the initial year of the pre-PDUFA era was made by simple data availability, which began in fiscal year 1980.

Finally, the list of NMEs and withdrawn NMEs may be deemed somewhat arbitrary given that there are examples of product withdrawals for lack of use (a.k.a. revenue) that may suggest reduced efficacy or intolerable side effects. These drug withdrawals are not accounted for in our analysis. Other NMEs have been withdrawn, but later reintroduced.

While several studies have investigated the withdrawal rate of NMEs (i.e., a Government Accountability Office study in 2002, and a 1999 FDA analysis published in the Journal of the American Medical Association) ${ }^{16}$, the fact that there are relatively few safety withdrawals, preand post-PDUFA, as compared to the total NMEs approved implies that the statistical power to detect significantly different safety withdrawal rates pre- and post-PDUFA is likely rather low. Combined with the additional issues regarding inherent ambiguity in determining the numerator/denominator, we recognize that there is room for continued debate and discussion of the withdrawal distribution and whether it has changed pre- and post-PDUFA. Thus we assess safety issues by making alternative bounding assumptions.. 


\section{B. Estimating the Potential Health Effects or Quality of Withdrawal}

Even though we believe there is no convincing evidence of differences in the distribution of market times pre-and post PDUFA, representing the quantity of safety withdrawals, there may be differences in the quality of drugs that were withdrawn. More precisely, in such cases the producer surplus would still be estimated by observed revenues, but when a drug is withdrawn appropriately, there may have been negative consumer surplus levels that more than offset the positive producer surplus, making the social surplus negative. Ideally, we would subtract the negative social surplus of such withdrawn drugs from the overall gain in surplus attributable to their initial more rapid approval. However, it is very difficult to estimate these negative consumer surplus effects of withdrawn drugs as it entails consumers paying for and consuming products that are claimed to make them worse off. Nonetheless, to assess the potential health effects of such unwanted consumption, we estimate the magnitude in the reduction in health that would eliminate the benefits of more rapid approval of drugs attributable to PDUFA. In Table 4 we report results from computing the equivalent amount of life years that must have been lost in order for PDUFA to have reduced social welfare. These estimates are derived from dividing the estimates of the benefits of speed (under 3\% discounting) by existing estimates of the value of a life year, which we assume range between $\$ 100,000$ and $\$ 300,000$.

The estimates in Table 4 indicate how many life years must have been lost on withdrawn drugs in order to offset the estimated gains in consumer surplus of non-withdrawn drugs, plus producer surplus gains from both withdrawn and non-withdrawn drugs. Table 4 indicates that for the lower bound on the social surplus, there must have been a loss of 70,000 life years when estimated at $\$ 100 \mathrm{~K}$ per life year, and 23,333 life years when estimated at $\$ 300 \mathrm{~K}$ per life year. Similarly, for the highest surplus estimated, the health loss must have been 310,000 to 103,333 
and for the lowest social gains estimated, withdrawn drugs must have caused a loss of 180,000 to 60,000 life years, depending on whether an additional life year is evaluated at $\$ 100 \mathrm{~K}$ or $\$ 300 \mathrm{~K}$, respectively.

\section{Estimating an Upper bound on The Adverse Safety effects of PDUFA}

For any estimates of the quality or safety effects of PDUFA one needs counterfactual estimates of the approval- and market times $(\mathrm{a}, \mathrm{m})$ in the absence of PDUFA for the withdrawn drugs observed under PDUFA, analogous to previous sections where we estimated counterfactual approval times in absence of PDUFA for non-withdrawn drugs.

We consider an extreme case in which all withdrawals after 1992, for drugs submitted for review after the passage of PDUFA I, were attributable to PDUFA and where there were no benefits associated with the drugs so that their social surplus was measured by the harmful health effects the withdrawn drugs imposed. More precisely, in this extreme case we assume the counterfactual approval times in the absence of PDUFA to be infinite, $a=\infty$, and thus corresponding to no welfare $\mathrm{W}(\infty, \mathrm{m})=0$. The change in welfare is thus

$$
\mathrm{W}(\infty, \mathrm{m})-\mathrm{W}(\mathrm{a}, \mathrm{m})
$$

This is a gain (loss) in welfare if the annual welfare $\mathrm{w}$ is negative (positive). In terms of this expression, this computation estimates a worst case scenario against PDUFA by estimating the highest welfare losses possible induced by PDUFA. For all the withdrawn drugs discussed here, we assume that the counterfactual approval time in absence of PDUFA would be infinite, $a=\infty$ (the drugs would never have been approved), implying that regardless of the assumption of the counterfactual market time, welfare vanishes, $W=0$. In addition, though an FDA induced withdrawal may be inefficient in the sense that those benefiting from a drug may outweigh the harms imposed, we assume that those benefits are zero for both consumers and producers so that 
the value of withdrawal is maximized by minimizing the negative annual value of the flow of pre-withdrawal surpluses $\mathrm{w}$.

We have calculated the adverse health effects associated with drugs withdrawn from the market that were submitted for review under PDUFA I and II using historical data available via The Adverse Event Reporting System (AERS) (http://www.fda.gov/cder/aers/extract.htm for the format of the data and limitations) which reports individual reports by drug and year, the age of the patient, and the type of adverse events experienced. Specifically, we investigated the drugs listed in Table 5.

In Table 6 we report the estimated cost in life years and calculated value in dollars of the drugs that were withdrawn. The AERS data were filtered to provide only deaths and hospitalizations for the selected drugs. For each drug, there were events that did not have an event date or age of the patient. An average of patient age and event date was calculated with the existing data for each drug and these values were then completed for the events with missing information. In order to calculate life years lost, we first had to establish life expectancies. Life expectancies were calculated for the period of 1990 and 2000 according to the US Census life tables published by the National Center for Health Statistics. For each individual we were able to establish a life expectancy that was specific for that individual's sex, age, and year of event (i.e., a 30 year-old male in 1990 has a different life expectancy than a 30 year-old male in 2000). In this analysis, we do not account for hospitalizations that did not result in a fatality and instead only focus on reported deaths. After calculating the estimated life years lost for each drug, we can estimate the cost by multiplying the life years either by $\$ 100,000$ or $\$ 300,000$, and discounting as appropriate. 
As shown in Table 6, adding up across the universe of withdrawn NMEs since the enactment of PDUFA, we find that this extreme upper bound entails around 55,600 life years lost. This upper bound is then compared to the gains in health implicit in the greater speed generated by PDUFA, which we estimated at the equivalent of 180,000 to 310,000 life years when valued at $\$ 100$ thousand per life year (see Table 4). Put differently, monetizing the lifeyears lost by $\$ 100$ thousand per year and discounting these monetized losses to 1992 dollars (at a real discount rate of $3 \%$ ) from the average year of the events leads to a value of $\$ 4.4$ billion, which is about 40 percent of the estimated value of speed at $\$ 11$ billion (see Table 2). Note that these calculations include Vioxx (rofecoxib) and Bextra( valdecoxib), which were both recently withdrawn, and whether any of them will eventually return to the market is as yet unclear. Additionally, we include Alosetron in our calculations; this drug has been returned to market with a more restrictive label.

Table 6 also reports the number of non-fatal hospitalizations reported for each drug, which in aggregate for all drugs amounts to approximately 16,000. Although the fatalities reported from these data seem more likely to be of lower error than hospitalizations, these hospitalizations, if valued substantially, could potentially lead to offsets larger than the gains of greater speed induced by PDUFA. However, we stress that these health effects are an extreme form of upper bounds on the adverse effects of PDUFA, based on the assumption that the withdrawn drugs had no benefits, that all the drugs that were withdrawn would never have been approved in the absence of PDUFA, and that all the individuals who died would have had an average life expectancy but for the consumption of the implicated drug. 


\section{DISCUSSION, LIMITATIONS, AND CONCLUDING REMARKS}

Our analysis is based on a number of assumptions and limitations. First, our benefit-cost and social surplus calculations are aggregated over all drug classes. Further research might fruitfully focus on disaggregating into specific therapeutic areas and "blockbuster" products.

Second, we have employed a product life cycle sales profile pattern based on data and analysis from IMS Health. Other life cycle sales profiles, such as that in the rate of return calculations by Grabowski, Vernon and DiMasi [2002] could be used instead; moreover, their framework allows for a more detailed free cash flow analysis that allows the intensity of marketing, manufacturing, and other costs to vary over the product life cycle. Although we have interpreted the relationships among social surplus and industry sales within the context of a linear demand curve, explicit nonlinear formulations of the demand curve are worthy of further examination. Moreover, though studies exist that indicate fairly little within class substitution across drugs, more general substitution patterns would of course allow for social surplus calculations that took into account offsets in producer and consumer surplus due to such substitution.

Third, the analysis reported here ends with NDAs/BLAs submitted to the FDA by the end of PDUFA-II (September 30, 2002), and approved by the FDA up through May 2004. It would be useful to update the approval data, to ensure that right censoring is not a significant issue.

Fourth, another limitation of our study is that the sales data used in the benefit calculations represent U.S. sales only. Foreign sales for drugs sold in the US are typically $75 \%$ to $100 \%$ of U.S. sales. The extent to which accelerated approval in the United States affected international approvals and launch dates was not incorporated into our calculations. If earlier 
U.S. approval encouraged more rapid approval abroad, then the NPV social surplus benefit of PDUFA would be greater than we have calculated.

Fifth, to the extent that accelerated FDA approval of NDAs/BLAs resulted in an increase in the duration of patent protection prior to patent expiration, it is possible that our calculations understate producers' benefits from PDUFA. Two considerations suggest that any such impact is likely to be rather small. First, patent expiration typically takes place 12 or so years following product launch ("effective patent life"), and thus viewed in present value terms at the beginning of PDUFA in 1992, such end of product life benefits are likely to be very small when discounted. ${ }^{17}$ Second, under the Hatch-Waxman Act, the maximum amount of time a drug could enjoy market exclusivity was set at 14 years (with possible 6-month extensions for sponsors proving efficacy in the pediatric population); precisely how many of the drugs in our sample would have run into this exclusivity ceiling is unclear, but the number is likely to be nontrivial. To the extent this would occur, accelerated FDA approval would not translate into longer effective patent life.

A final limitation of our study is that we have not undertaken a separate analysis of "fast track" provisions that involve rolling submissions to the FDA. We believe the impact of this omission is likely to be relatively minor, for not only is the number of NDAs/BLAs granted fast track study in our sample up through 2002 likely to be small, but preliminary analyses by several researchers suggests that the differential impact of fast track from priority status on approval times is small, and in some cases fast track may even lengthen approval times. ${ }^{18}$

The methodology and framework proposed could be extended to numerous policies beyond PDUFA, such as, for example, facilitating more rapid FDA approvals by allowing greater use of surrogate markers as endpoints, while simultaneously requiring enhanced post- 
approval surveillance and monitoring efforts. Since the clinical development time between filing of the Investigational New Drug application and submission of the NDA/BLA is two to four times larger than review time of the NDA/FDA at the FDA, the framework developed here might be useful in examining potential costs and benefits of various other policies that could affect the critical pathway from pre-clinical discovery through submission of an NDA/BLA. More generally, in our judgment much more work is warranted providing more evidence-based and quantitative assessment on the many types of FDA policies that affect the US and other populations. 


\section{FIGURES AND TABLES}

Figure 1: Producer and Consumer Surplus for a given Review and Market Time

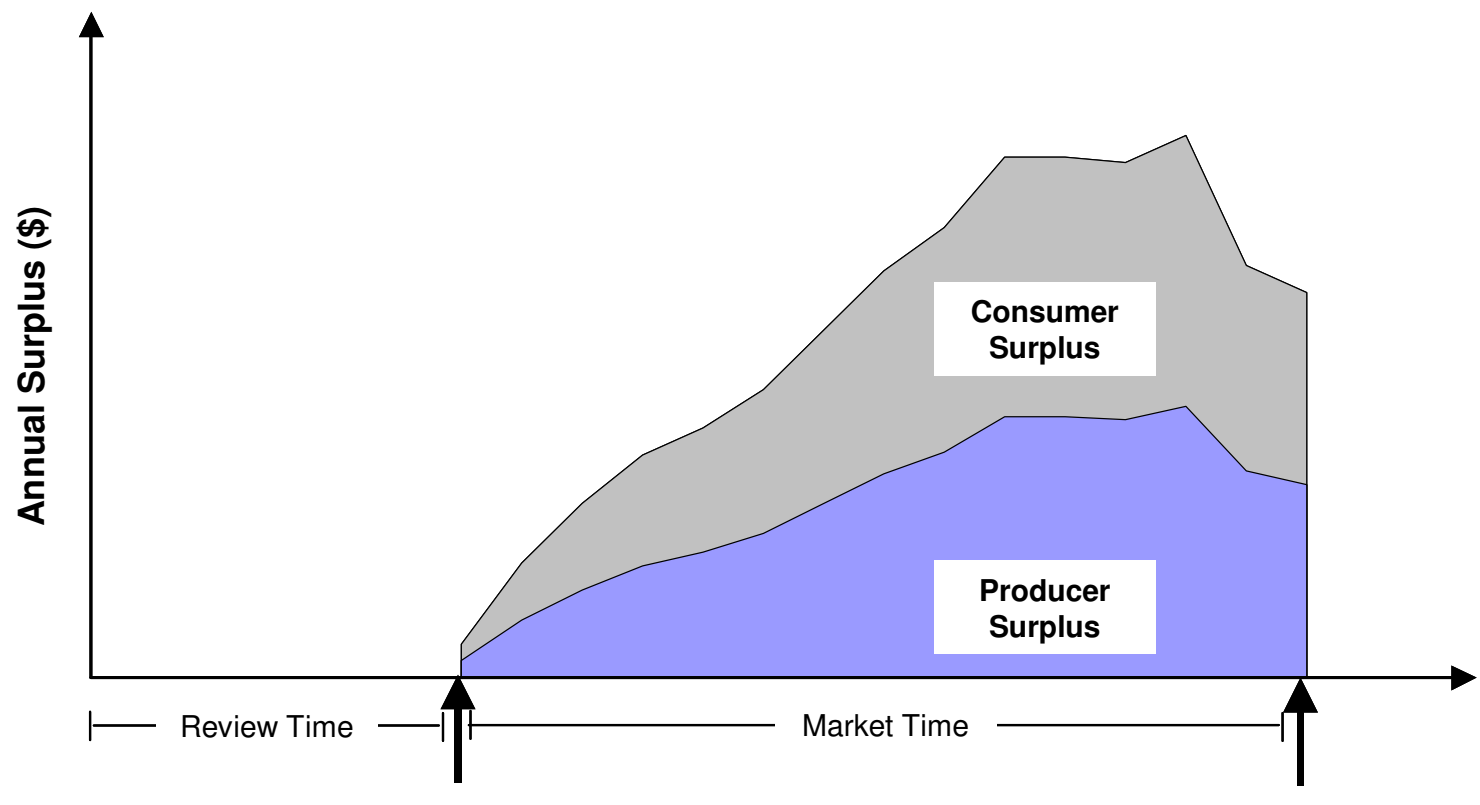

FDA Approved

Withdrawal

Time

Figure 2: Survival Curve for NMEs pre and post PDUFA

Survival Curves for STANDARD Designated NMES

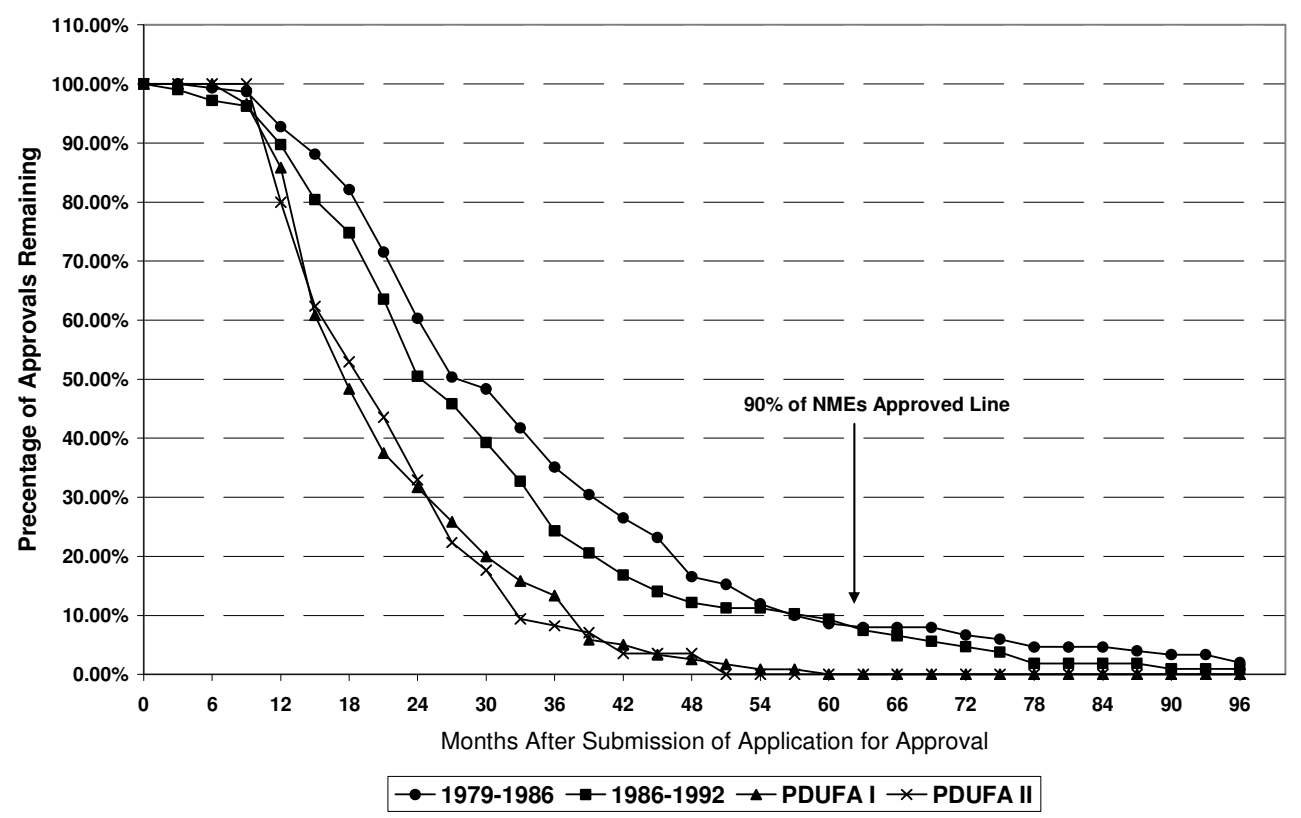


Figure 3: Survival Curves depicting NME withdrawal rates pre and post PDUFA

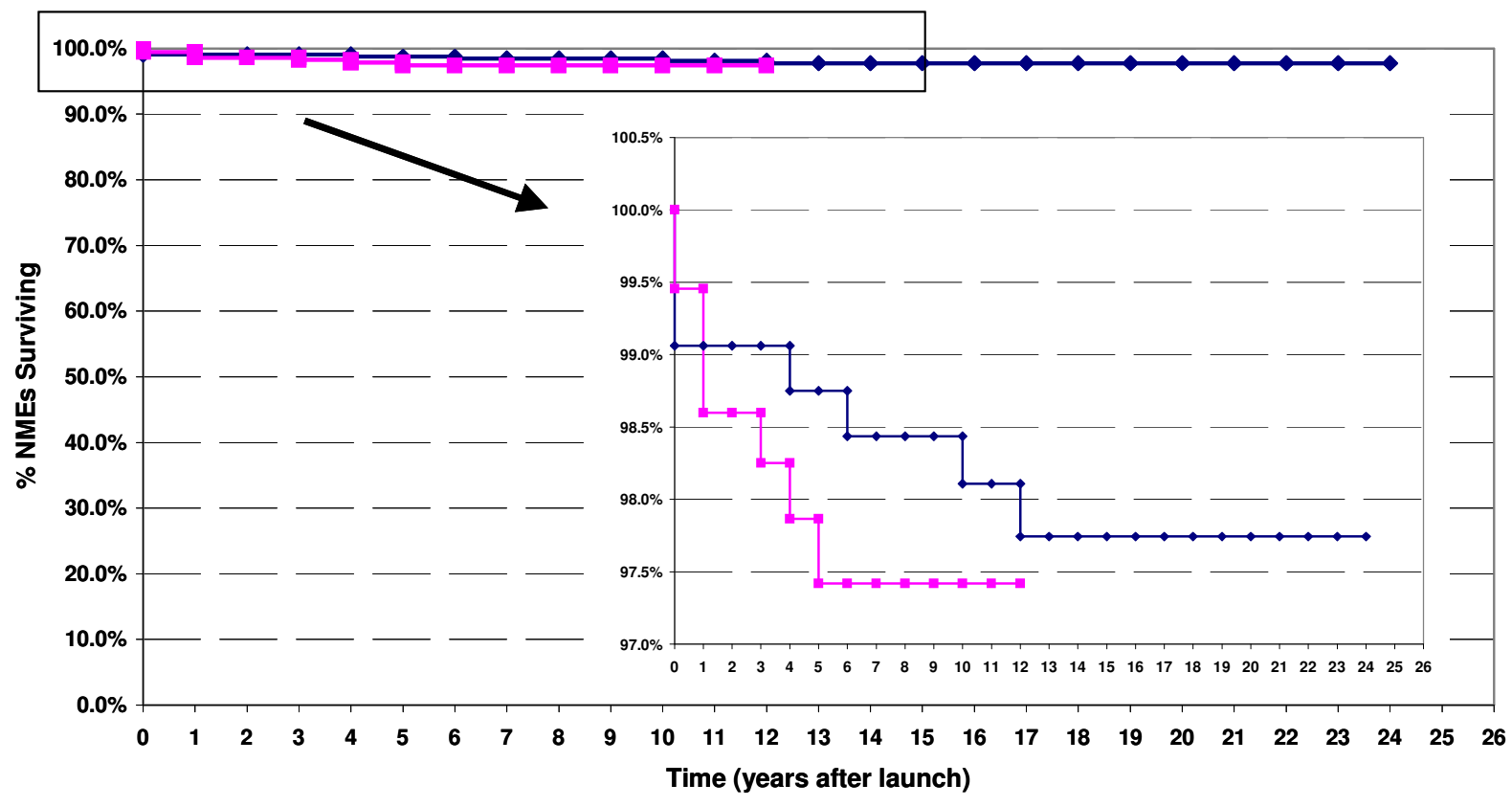


Table 1: Estimated Effects of PDUFA-I and PDUFA-II on Approval Times

\begin{tabular}{|c|c|c|c|c|}
\hline \multirow[b]{2}{*}{ Variable } & \multicolumn{2}{|c|}{$\begin{array}{l}\text { Aggregate Specification } \\
\text { for PDUFA Time Trends }\end{array}$} & \multicolumn{2}{|c|}{$\begin{array}{l}\text { Drug Class Specification } \\
\text { for PDUFA Time Trends }\end{array}$} \\
\hline & Coefficient & P-Value & Coefficient & P-Value \\
\hline Intercept Constant & 3.515 & $<0.001$ & 3.524 & $<0.001$ \\
\hline Natural Log IND to NDA time & -0.001 & 0.965 & -0.012 & 0.695 \\
\hline Time Trend & -0.017 & 0.038 & -0.016 & 0.050 \\
\hline Priority Review & -0.490 & $<0.001$ & -0.487 & $<0.001$ \\
\hline PDUFA I Time Trend & -0.081 & 0.001 & -0.080 & 0.001 \\
\hline PDUFA II Time Trend & -0.037 & 0.018 & -0.029 & 0.062 \\
\hline IND to NDA Data Missing & 0.103 & 0.521 & 0.055 & 0.728 \\
\hline Orphan Drug & 0.109 & 0.094 & 0.114 & 0.078 \\
\hline Domestic Company Sponsor & -0.072 & 0.115 & -0.074 & 0.100 \\
\hline Cardiovascular & 0.120 & 0.203 & 0.136 & 0.144 \\
\hline Anti-Infectives & -0.306 & 0.001 & -0.294 & 0.002 \\
\hline Anti-Neoplastics & -0.304 & 0.009 & -0.143 & 0.276 \\
\hline CNS & 0.128 & 0.211 & 0.143 & 0.159 \\
\hline AIDS & -0.812 & $<0.001$ & -0.805 & $<0.001$ \\
\hline Metabolic/Endocrine & -0.062 & 0.514 & -0.056 & 0.550 \\
\hline Gastrointestinal & -0.088 & 0.516 & -0.069 & 0.607 \\
\hline Dermatology/Opthalomology & -0.188 & 0.087 & -0.179 & 0.101 \\
\hline Anti-Inflammatories & 0.101 & 0.505 & 0.322 & 0.061 \\
\hline Radiopharmaceuticals & 0.183 & 0.122 & 0.202 & 0.085 \\
\hline Respiratory & 0.288 & 0.041 & 0.309 & 0.027 \\
\hline Other & -0.352 & 0.019 & -0.334 & 0.025 \\
\hline Anti-Inflammatory PDUFA II Time Trend & N/A & N/A & -0.114 & 0.007 \\
\hline Anti-Neoplastic PDUFA II Time Trend & N/A & $\mathrm{N} / \mathrm{A}$ & -0.064 & 0.011 \\
\hline $\begin{array}{l}R \text {-squared } \\
\text { Observations }\end{array}$ & & & $\begin{array}{l}\text { R-squared } \\
\text { Observations }\end{array}$ & $\begin{array}{r}0.405 \\
662\end{array}$ \\
\hline
\end{tabular}

Table 2: The Effects on producer surplus of PDUFA I and II

\$'s (Billions)

\begin{tabular}{|c|c|c|c|c|c|c|c|c|c|c|}
\hline \multirow[t]{3}{*}{ 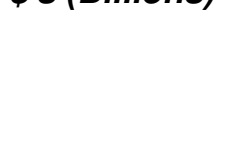 } & \multicolumn{4}{|c|}{$\beta=1 / 1.03$} & \multicolumn{6}{|c|}{$\beta=1 / 1.09$} \\
\hline & \multicolumn{3}{|c|}{ Counter } & \multirow[b]{2}{*}{$\%$ Diff } & \multirow{2}{*}{\multicolumn{3}{|c|}{$\begin{array}{cc}\text { Counter } \\
\text { PDUFA }\end{array}$}} & \multirow{2}{*}{\multicolumn{2}{|c|}{ Difference }} & \multirow{3}{*}{$\begin{array}{r}\% \text { Diff } \\
3.7 \%\end{array}$} \\
\hline & PDUFA & factual & Difference & & & & & & & \\
\hline Sales & $\overline{\$ \$ 1,149}$ & $\$ 1,134$ & 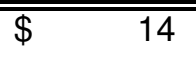 & $\overline{1.3 \%}$ & \$ \$482 & 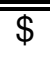 & 4465 & 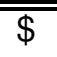 & 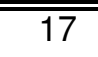 & \\
\hline PDUFA Costs & $\$ 0.89$ & $\$$ & 0.89 & $\mathrm{~N} / \mathrm{A}$ & $\$ 0.39$ & $\$$ & - & $\$$ & 0.39 & $\mathrm{~N} / \mathrm{A}$ \\
\hline Variable Costs & $\$ 230$ & $\$ \quad 227$ & 3 & $1.3 \%$ & $\$ \quad 96$ & $\$$ & 93 & $\$$ & 3 & $3.7 \%$ \\
\hline Net & $\$ 918$ & $\$ 907$ & 11 & $1.2 \%$ & $\$ 385$ & $\$$ & 372 & $\$$ & 13 & $3.6 \%$ \\
\hline
\end{tabular}


Table 3: The Effects on Social Surplus of PDUFA I and II

$\begin{array}{cc} & \text { \$'s Billions } \\ \text { Row } & \\ & \text { Sales Bound on Social Surplus } \\ \text { A } & \text { Before Expiration } \\ \text { B } & \text { After Expiration } \\ & \text { Highest Consumer Surplus Case } \\ \text { C } & \text { Before Expiration } \\ \text { D } & \text { After Expiration } \\ \text { E } & \text { Total Consumer Surplus } \\ \text { F } & \text { Total Social Surplus } \\ & \text { Lowest Consumer Surplus Case } \\ \text { G } & \text { Before Expiration } \\ \text { H } & \text { After Expiration } \\ \text { I } & \text { Total Consumer Surplus } \\ \boldsymbol{J} & \text { Total Social Surplus }\end{array}$

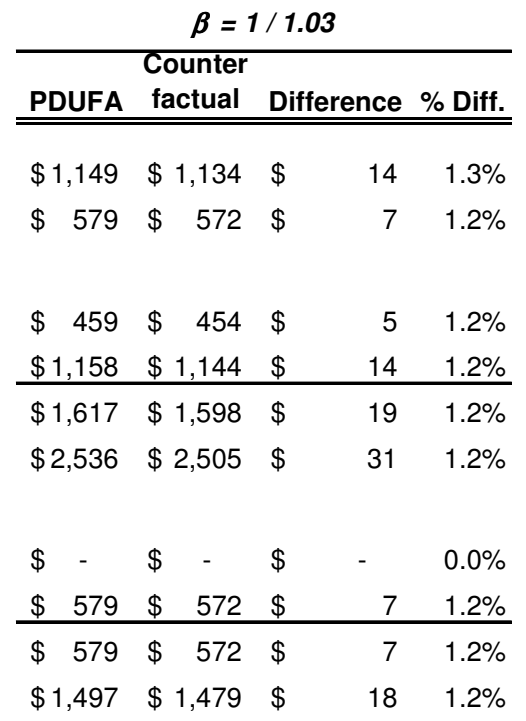

\begin{tabular}{lllllrl}
\multicolumn{6}{c}{$\boldsymbol{\beta}=\mathbf{1} / \mathbf{1 . 0 9}$} \\
\hline & \multicolumn{7}{c}{ Counter } \\
PDUFA & factual & Difference & $\%$ Diff. \\
\hline \hline & & & & & & \\
$\$$ & 482 & $\$$ & 465 & $\$$ & 17 & $3.7 \%$ \\
$\$$ & 130 & $\$$ & 125 & $\$$ & 5 & $4.0 \%$ \\
& & & & & & \\
$\$$ & 192 & $\$$ & 186 & $\$$ & 7 & $3.6 \%$ \\
$\$$ & 260 & $\$$ & 250 & $\$$ & 10 & $4.0 \%$ \\
\hline$\$$ & 452 & $\$$ & 436 & $\$$ & 17 & $3.8 \%$ \\
$\$$ & 838 & $\$$ & 808 & $\$$ & 30 & $3.7 \%$ \\
& & & & & & \\
$\$$ & - & $\$$ & - & $\$$ & - & $0.0 \%$ \\
$\$$ & 130 & $\$$ & 125 & $\$$ & 5 & $4.0 \%$ \\
\hline$\$$ & 130 & $\$$ & 125 & $\$$ & 5 & $4.0 \%$ \\
$\$$ & 515 & $\$$ & 497 & $\$$ & 18 & $3.7 \%$
\end{tabular}

Table 4: Estimate of Life Years Impacted to Offset Benefits of PDUFA I and PDUFA II

\begin{tabular}{lcrr} 
& $\begin{array}{c}\text { PDUFA Benefit } \\
\text { \$ Billions }\end{array}$ & $\begin{array}{c}\text { Life Years Valued } \\
\text { at } \mathbf{\$ 1 0 0 K}\end{array}$ & $\begin{array}{r}\text { Life Years Valued } \\
\text { at \$300K }\end{array}$ \\
\cline { 2 - 4 } Social Surplus Lower Bound & $\$ 7$ & 70,000 & 23,333 \\
Social Surplus High Consumer Surplus & $\$ 31$ & 310,000 & 103,333 \\
Social Surplus Low Consumer Surplus & $\$ 18$ & 180,000 & 60,000
\end{tabular}


Table 5: List of NMEs submitted during PDUFA I/II that were subsequently withdrawn for safety reasons

\begin{tabular}{lccc}
\hline Drug Name & NDA Submission Date & Year Approved & Year Withdrawn \\
\hline \hline Bromfenac & Dec 30, 1994 & 1997 & 1998 \\
Cerivastatin & Jul 26, 1996 & 1997 & 2001 \\
Grepafloxin & Nov 08, 1996 & 1997 & 1999 \\
Mibefradil & Mar 11, 1996 & 1997 & 1998 \\
Troglitazone & Aug 01, 1996 & 1997 & 2000 \\
Rapacuronium & Jun 25, 1998 & 1999 & 2001 \\
Rofecoxib*** & Nov 23, 1998 & 1999 & 2004 \\
Alosetron** & Jun 30, 1999 & 2000 & 2000 \\
Valdecoxib*** & Jan 16, 2001 & 2001 & 2005 \\
${ }^{*}$ Not considered an NME & & \\
${ }^{* *}$ Returned to market in 2002 w/ restrictions & & \\
${ }^{* * *}$ Not in CDER's 2004 Report to Nation - added by authors &
\end{tabular}

Table 6: Estimated cost of NMEs withdrawn from market that were submitted for review during PDUFA I/II

\begin{tabular}{|c|c|c|c|c|c|c|c|c|c|c|}
\hline \multirow[b]{2}{*}{ Drug Name } & \multirow{2}{*}{$\begin{array}{c}\text { \# of } \\
\text { Hospitilzations } \\
\text { Not Resulting in } \\
\text { Death }\end{array}$} & \multirow[b]{2}{*}{$\begin{array}{c}\text { \# of } \\
\text { Deaths }\end{array}$} & \multirow[b]{2}{*}{$\begin{array}{c}\text { Average } \\
\text { year of } \\
\text { event }\end{array}$} & \multirow[b]{2}{*}{$\begin{array}{l}\text { Life Years } \\
\text { Lost }^{\star}\end{array}$} & \multirow[b]{2}{*}{$\begin{array}{c}\text { Cost at } \$ 100 \mathrm{~K} \\
\text { per Life Year (\$ } \\
\text { M) }\end{array}$} & \multirow[b]{2}{*}{$\begin{array}{c}\text { Cost at } \$ 300 \mathrm{~K} \\
\text { per Life Year } \\
(\$ \mathrm{M})\end{array}$} & \multicolumn{2}{|c|}{$\beta=1 / 1.03$} & \multicolumn{2}{|c|}{$\beta=1 / 1.09$} \\
\hline & & & & & & & $\begin{array}{l}\text { Cost at } \$ 100 \mathrm{~K} \\
\text { per Life Year } \\
(1992 \$ \mathrm{M})\end{array}$ & $\begin{array}{c}\text { Cost at } \$ 300 \mathrm{~K} \\
\text { per Life Year } \\
(1992 \$ \mathrm{M})\end{array}$ & $\begin{array}{c}\text { Cost at } \$ 100 \mathrm{~K} \\
\text { per Life Year } \\
(1992 \$ \mathrm{M})\end{array}$ & $\begin{array}{c}\text { Cost at } \$ 300 \mathrm{~K} \\
\text { per Life Year } \\
(1992 \$ \mathrm{M})\end{array}$ \\
\hline Alosetron & 685 & 46 & 2000 & 1,037 & 104 & 311 & 81 & 244 & 51 & 153 \\
\hline Bromfenac & 257 & 77 & 1998 & 1,787 & 179 & 536 & 151 & 453 & 109 & 328 \\
\hline Cerivastatin & 4,455 & 883 & 2000 & 14,086 & 1,409 & 4,226 & 1,099 & 3,297 & 683 & 2,049 \\
\hline Grepafloxacin & 72 & 13 & 1998 & 228 & 23 & 68 & 19 & 57 & 13 & 40 \\
\hline Mibefradil & 665 & 129 & 1998 & 2,029 & 203 & 609 & 172 & 517 & 126 & 377 \\
\hline Rapacuronium & 22 & 11 & 2000 & 516 & 52 & 155 & 41 & 122 & 26 & 77 \\
\hline Rofecoxib & 8,013 & 1,349 & 2001 & 21,815 & 2,181 & 6,544 & 1,669 & 5,007 & 999 & 2,998 \\
\hline Troglitazone & 1,444 & 688 & 1998 & 13,048 & 1,305 & 3,914 & 1,094 & 3,282 & 780 & 2,341 \\
\hline Valdecoxib & 581 & 56 & 2003 & 1,056 & 106 & 317 & 77 & 231 & 42 & 126 \\
\hline TOTAL & 16,194 & 3,252 & & 55,601 & 5,560 & 16,680 & 4,403 & 13,209 & 2,830 & 8,490 \\
\hline
\end{tabular}




\section{FOOTNOTES}

${ }^{1}$ See, for example, Sam Peltzman [1974], The Regulation of Pharmaceuticals: Balancing the Benefits and Risks, Washington DC: American Enterprise Institute for Policy Research; Mary K. Olson [1997], "Firm Characteristics and the Speed of FDA Approval", Journal of Economics and Management Strategy, Summer, 377-401; Olson [1998], "Pharmaceutical Regulation", in The New Palgrave Dictionary of Economics and the Law, Peter Newman, ed., New York: Stockton Press, 40-45; Olson [2005], "Managing Delegation with User Fees: Reducing Delay in New Drug Review", Journal of Health Politics, Policy and Law, forthcoming; Daniel P. Carpenter [2002], "Groups, the Media, Agency Waiting Costs, and FDA Drug Approval", American Journal of Political Science, July, 490-505; and Michael Dickson and Jean Paul Gagnon [2004], "Key Factors in the Rising Cost of New Drug Discovery and Development", Nature Reviews: Drug Discovery, 3, May, 417-429. ..

${ }^{2}$ The only related study of which we are aware that assesses costs and benefits of regulations is that by Sam Peltzman, who examined growth in market shares of drugs launched prior to 1962 to those launched after the 1962 Kefauver-Harris Amendments were passed by Congress. See Sam Peltzman [1973], "Evaluation of Consumer Protection Legislation - 1962 Amendments", Journal of Political Economy, 81(5), 1049-1091; this research is also discussed in Peltzman [1974], supra.

${ }^{3}$ U.S. Food and Drug Administration, FY 2002 PDUFA Financial Report [2003], p. 6, and p. 9.

${ }^{4}$ Much of the material that follows is taken from Ernst Berndt, Adrian Gottschalk, Tomas Philipson and Matthew Strobeck [2005], "Industry Funding of the FDA: Effects of PDUFA on Approval Times and Withdrawal Rates", Nature Reviews: Drug Discovery, 4, July, 545-554; and by the same authors, "Assessing the Impacts of the Prescription Drug User Fee Acts (PDUFA) on the FDA Approval Process", Cambridge, MA: National Bureau of Economic Research, Working Paper No. 10822, October 2004. Forthcoming in David M. Cutler and Alan M. Garber, eds., Frontiers in Health Policy, Vol. 8, Cambridge, MA: MIT Press for the National Bureau of Economic Research, late 2005.

${ }^{5}$ U.S. Food and Drug Administration [2004], "Prescription Drug User Fees-Overview", U.S. Food and Drug Administration [online] (cited 27 April 2004), http://www.fda.gov.oc/pdufa/overview.html.

${ }^{6}$ U.S. Food and Drug Administration [2004], "PDUFA Reauthorization Performance Goals and Procedures", U.S. Food and Drug Administration [online], (cited 27 April 2004),

$<$ http://www.fda.gov/oc/pdufa/PDUFAIIIGoals.html>.

${ }^{7}$ See Berndt, Gottschalk, Philipson and Strobeck [2005], supra. .

${ }^{8}$ A $0 \%$ discount rate assumes there is no time value for moneys, and is therefore implausible. 
The NIH Cost-effectiveness panel suggested using 3\% as a preferred real discount rate, but also recommended assessing sensitivity at $0 \%, 5 \%$ (used most commonly) and 7\%. See Martha R. Gold, Joanna E. Siegel, Louise B. Russell, and Milton C. Weinstein, eds., Cost-Effectiveness in Health and Medicine, New York: Oxford University Press, 1996. The Office of Management and Budget has recently recommended use of 3\% and $7 \%$ real discount rates, the former to capture intergenerational discounting, and the latter representing an estimate of the average before-tax rate of return to private capital in the U.S. See Office of Management and Budget [2003], Regulatory Analysis: Circular A-4, September 17, pp. 31-34. Finally, in their recent cost of drug development analyses, DiMasi and coauthors use $11 \%$ as the real cost of capital. See Joseph A. DiMasi, Ronald W. Hansen and Henry G. Grabowski [2003], "The Price of Innovation: New Estimates of Drug Development Costs", Journal of Health Economics, 22:2, March, 151-185; and Grabowski, John Vernon and DiMasi [2002], "Returns on Research and Development for 1990s New Drug Introductions", PharmacoEconomics, 20 (Supplement 3), 11 29.

${ }^{9}$ The U.S. Food and Drug Administration provided IMS sales data via a signed contract involving Professor Berndt of the MIT Sloan School of Management, the FDA and IMS Health.

10 The information on life cycle sales is taken from "An Analysis of Launch-to-Peak Sales for NCEs", in M. P. Mathiew, ed., PAREXEL's Pharmaceutical Statistical Sourcebook 2003/2004, p. 46.

${ }^{11}$ Average sales as a percent of peak sales were, for years 1 through $15,6 \%, 21 \%, 32 \%, 41 \%$, $46 \%, 53 \%, 64 \%, 75 \%, 83 \%, 96 \%, 96 \%, 95 \%, 100 \%, 76 \%$ and $71 \%$, respectively.

${ }^{12}$ For 56 of the 341 NDAs/BLAs submissions filed during PDUFA-I and II and approved up to May 2004, there is no sales data in the IMS Health data set. These could include drugs whose sales did not meet a minimum reporting threshold, or drugs approved but never marketed. We also excluded one drug from the anti-infective class since it was withdrawn from the US market.

${ }^{13}$ Supplemental applications and approvals are discussed in greater detail in Ernst R. Berndt, Iain M. Cockburn and Karen Grepin, "Biopharmaceutical R\&D: Is the Productivity Decline Overstated?", paper presented at the Conference on "Health Reform in Europe and the United States: Is There Common Ground?", Tufts European Center, Talloires, France, July 13-15, 2005. Available upon request from eberndt@ mit.edu.

${ }^{14}$ Henry G. Grabowski and John M. Vernon [1992], "Brand Loyalty, Entry, and Price Competition in Pharmaceuticals After the 1984Drug Act", Journal of Law and Economics, Vol. 35, October, 331-350; Ernst R. Berndt, Iain M. Cockburn and Zvi Griliches [1996], "Pharmaceutical Innovations and Market Dynamics: Tracking Effects on Price Indexes for Antidepressant Drugs", Brookings Papers: Microeconomics 1996, 133-188.

${ }^{15}$ See Berndt, Gottschalk, Philipson and Strobeck [2005], supra. 
16 These and other related studies are referenced in Berndt, Gottschalk, Philipson and Strobeck [2005], supra.

${ }^{17}$ See, for example, Henry G. Grabowski and John Vernon [2000], "Effective Patent Life in Pharmaceuticals", International Journal of Technology Management, 19, 98-100.

${ }^{18}$ See, for example, Christopher Milne and E. M. Bergman [2001], "Fast Track Designation Under the Food and Drug Administration Modernization Act: The Industry Experience," Drug Information Journal, 35:1, 71-83; also see Lisa Piercey [2003], "Life in the Fast Lane", Signals [online], http://signalsmag.com/signalsmag.nsf/, May 23, 1-14. 